\title{
Behind Armour Blunt Trauma - an emerging problem
}

\author{
L Cannon
}

\begin{abstract}
Behind Armour Blunt Trauma (BABT) is the non-penetrating injury resulting from the rapid deformation of armours covering the body. The deformation of the surface of an armour in contact with the body wall arises from the impact of a bullet or other projectile on its front face. The deformation is part of the retardation and energy absorbing process that captures the projectile. In extreme circumstances, the BABT may result in death, even though the projectile has not perforated the armour. An escalation of the available energy of bullets and the desire of armour designers to minimise the weight and bulk of personal armour systems will increase the risk of BABT in military and security forces personnel.
\end{abstract}

In order to develop materials that can be interposed between the armour and the body wall to attenuate the transfer of energy into the body, it is essential that the mechanism of BABT is known. There is a great deal of activity within UK and NATO to unravel the interactions; the mechanism is likely to be a combination of stress (pressure) waves generated by the rapid initial motion of the rear of the armour, and shear deformation to viscera produced by gross deflection of the body wall.

Physical and computer model systems are under development to characterise the biophysical processes and provide performance targets for materials to be placed between armours and the body wall in order to attenuate the injuries (trauma attenuating backings - TABs).

The patho-physiological consequences of BABT are being clarified by research, but the injuries will have some of the features of blunt chest trauma observed in road traffic accidents and other forms of civilian blunt impact injury. The injuries also have characteristics of \section{primary blast injury. An overview diagnosis and treatment is described. \\ Surg Lt Cdr \\ L Cannon, BSc MB BS \\ FRCS Dip Sports Med} $\mathrm{RN}$

Orthopaedic Specialist Registrar

Orthopaedic Dept,

Queen Alexandra

Hospital, Cosham,

Hants, PO6 3LY

\section{Introduction}

Behind armour blunt trauma (BABT) is the spectrum of non-penetrating injuries to the torso resulting from the impact of projectiles on personal armours. Although the armour may stop the actual penetration of the projectile through the armour, the energy deposited in the armour by the retarded projectile may be transferred through the armour backing and body wall. It may produce serious injury to the thoracic and abdominal contents behind the plate. With very high energy bullet impacts, the thoracic injuries may result in death.

The existence of BABT as a clinical entity was first reported in 1978 by Carroll and Soderstrom among police officers wearing flexible body armour struck by handgun bullets. BABT may occur behind flexible textile-based armours and also behind rigid armours, principally constructed from ceramic materials.

BABT has been identified as an emerging problem that has implications for the designers of personal armour systems, the operational performance of soldiers and for medical management of casualties. There are two principal reasons for its growing prominence:

- An increase in the calibre and available energy of bullets that may be used in peace-keeping and other operational scenarios;

- The desire of the designers of personal armour systems to reduce the weight and thickness of soft armours and armour plates - a strategy that plainly will buy benefit in terms of the burden on military personnel, but will exacerbate the problem of dissipating the energy in the armour system. Armours are designed to absorb energy but the rapid deformations of the armours may result in a greater proportion of the energy of the retarded projectile being propagated into the body.

The energy transferred from armours may be absorbed, dissipated or redistributed using materials placed between the armour system and the body - these materials are called Trauma Attenuating Backings (TABs). There is research activity within NATO to develop the scientific basis for the design of TABs.

This paper outlines the current views on the pathophysiology and biophysical mechanisms of BABT, and describes 
technical approaches to developing model systems to characterise the BABT threat behind armours. A brief overview on the medical management of blunt injury to the thorax is also presented.

\section{The ballistic threat against armour plates}

The ballistic threat against soldiers continues to rise, both in terms of bullet calibre and available energy. United Kingdom armed forces use rifles that fire bullets of principally $5.56 \mathrm{~mm}$ calibre (e.g. the SA-80); the most ubiquitous weapons deployed by irregular forces fire $7.62 \mathrm{~mm}$ calibre projectiles (e.g. the AK-47). Rifles are available which fire bullets of $12.7 \mathrm{~mm}$ calibre; this calibre was largely developed to fire ball and armour piercing rounds against vehicles and lightly defended structures. Rifles and other types of gun firing $12.7 \mathrm{~mm}$ bullets are in service with the majority of major armies (Jane's Infantry Weapons 1999). During the early 1990's, $12.7 \mathrm{~mm}$ rounds were fired against British soldiers in Northern Ireland (Gotts 1998a), and caused fatalities. It has been reported in the press that the Royal Ulster Constabulary believe that the Provisional Irish Republican Army (PIRA) are in possession of a number of Barratt rifles that fire $12.7 \mathrm{~mm}$ rounds (The Sunday Times 7 May 2000).

The $12.7 \mathrm{~mm}$ calibre bullet is emerging as a direct anti-personnel weapon. Modern armies routinely deploy armour plates that are designed to stop 5.56/7.62 $\mathrm{mm}$ calibre bullets. The significantly higher energy of the $12.7 \mathrm{~mm}$ bullet will inevitably result in perforation of these plates. It is technically feasible to develop armour plates that will stop $12.7 \mathrm{~mm}$ ammunition, but the dissipation of the enormous quantities of energy raises the issue of BABT injury, which in extreme cases may result in death. Representative available energies at the gun muzzle for $7.62 \mathrm{~mm}$ (standard NATO issue) and $12.7 \mathrm{~mm}$ (Soviet B-32, armour piercing

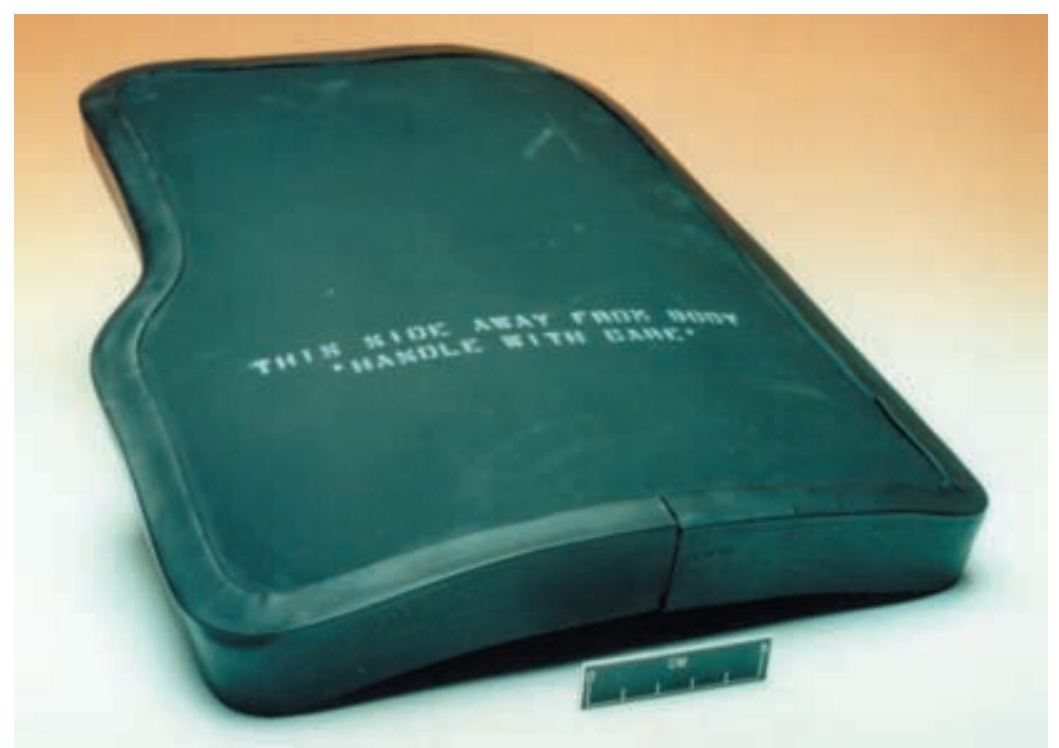

Fig 1. A commercial boron carbide armour plate capable of stopping $12.7 \mathrm{~mm}$ bullets. incendiary) are $3.5 \mathrm{~kJ}$ and $14 \mathrm{~kJ}$ respectively. NATO has reviewed the threat from BABT in military operations. A Specialist Team on Body Armour (Knudsen 1996) concluded from the available knowledge that:

- the BABT injury potential of defeated high-energy bullets (i.e. $12.7 \mathrm{~mm}$ calibre) was significant;

- that of $7.62 \mathrm{~mm}$ bullets was largely dependent on the armour design;

- there was no evidence of significant BABT injury from $5.56 \mathrm{~mm}$ military bullets.

Another potential source of BABT injury arises from the detonation of explosives encased within metal containers. Although conventional munitions are designed to produce very large numbers of small fragments with uniform mass and low energy, certain improvised explosive devices may generate large metallic fragments with very high available energies. The impact of these fragments either individually, or as a shower upon the armour plates of Explosive Ordnance Disposal (EOD) suits may transfer sufficient energy during the retardation process to produce BABT injuries.

\section{Personal body armour design}

The use of body armour dates to antiquity. The development of body armour for protection against bullets and fragments began during the American Civil War (Peterson 1950) with the Korean War providing the catalyst for modern scientific study (Coates and Beyer 1962). The current commercially available body armours share similar features. The main types of armour in service with the British Army include 'soft', flexible armours and ceramic-based, 'rigid' armour plates.

The flexible armours comprise layers of aramid and/or nylon to dissipate the kinetic energy of a projectile (either low-energy bullets or fragments) by stretching fibres. The most common aramid - Kevlar ${ }^{\circledR}$ - was originally developed by DuPont (USA) as a replacement for steel belting in vehicle tyres but the research division of the US National Institute of Justice (NIJ) recognised that it might prove a replacement for nylon in personal armours. It became apparent that it was superior to nylon and its use is now ubiquitous.

Rigid plates usually have three components: a hard, brittle ceramic strike face acting as a bullet eroder and energy dissipater, an energy absorbing backing to the ceramic (frequently an aramid composite) and the adhesive binding the two materials. Improved Northern Ireland Body Armour (INIBA) plates are composed of an alumina ceramic $\left(\mathrm{Al}_{2} \mathrm{O}_{3}\right)$ and will defeat $7.62 \mathrm{~mm}$ rounds. A commercially available boron carbide plate capable of stopping a 


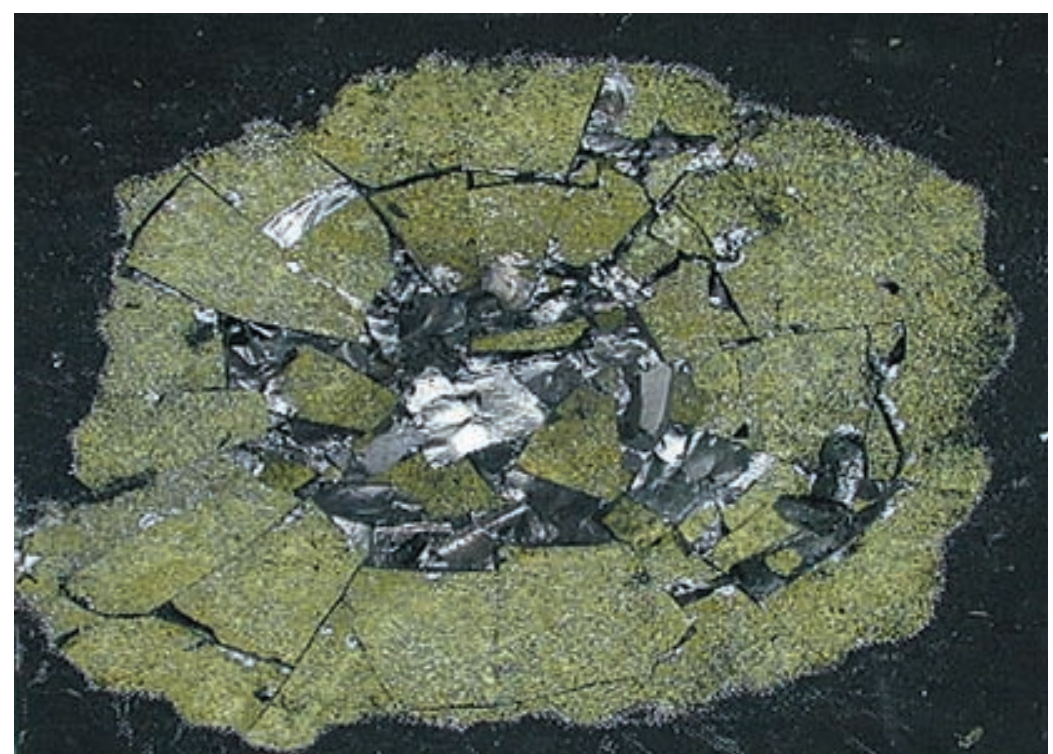

Fig 2. The brittle fracture on the impact face of a boron carbide plate (the black aramid spall shield has been removed). found in an article by Shepard et al (1969). He describes the case of a US Army sergeant accidentally shot with an M-16 round at close range during the Vietnam War. There is no mention of 'rigid' body armour or other retardation but the round did not penetrate the pleural cavity. After a short period of respiratory and haemodynamic stability the patient rapidly deteriorated and died within 45 minutes of admission. Massive pulmonary contusions alone were seen at post-mortem.

In a civilian setting, Carroll and Soderstrom (1978) described 5 cases of BABT in police officers wearing Kevlar ${ }^{\circledR}$ soft body armour struck by handgun bullets. All survived with no significant cardiorespiratory sequelae.

The lethal effects of a higher energy round (.45 inch) fired at close range against soft armour (undefeated) were reported by Thomas (1982). The energy transfer greatly exceeded the limits of the vest but these cases do exemplify that over a certain range of energy transfers to the chest, a clinical picture will develop anywhere on the spectrum between minor and non-survivable injury.

One of the few accurately documented examples of significant but survivable BABT was presented as recently as 1995 (Jourdan 1995). A humanitarian aid worker in Sarajevo was struck by a Soviet $14.5 \mathrm{~mm}$ bullet (at unknown range) while wearing 'complete' body armour. Apart from skin and muscle damage his cardio-respiratory status was stable. A chest radiograph revealed no rib fractures and a small haemothorax only, which was managed with a chest drain. A subsequent radiograph on the same day revealed a developing pulmonary contusion corresponding to the site of impact. The patient made an uneventful recovery.

Body armour reduces the incidence of torso injury while shifting the worst injured areas to the extremities (Mehran 1995). This shift has been confirmed by the Canadian Casualty Database Project which has been gathering casualty statistics from the former Yugoslavia since 1992 (Gotts 1998a). The Canadians have also concluded that wearing body armour decreases wounding potential (from fragmentation injury as well as bullets) and that there have been no reported instances where the wearing of armour has exacerbated injury.

The important issue with BABT is that historically it has been associated with the defeat of low energy bullets (such as from hand-guns) by flexible textile armour systems. Many armour manufacturers offer "trauma backings" to reduce these injuries behind soft armours. However, it is now emerging as a significant military problem, particularly behind rigid armour plates designed to defeat high energy bullets. There is little biophysical and pathophysiological 
information on which to base designs for TABs to counter the very high rates of energy transfer to the body under these circumstances.

\section{Mechanism of thoracic injury from BABT}

BABT is a specific form of blunt chest trauma (BCT). Experimental studies on animal models, computer modelling of the transfer of energy into the body and review of clinical data have enabled an understanding of the biophysical principles of BCT (Cooper and Taylor 1989).

General principles of blunt impacts to the body

A blunt impact to the body may produce local and distant injuries. Motion of the body wall transfers energy from the impactor to the viscera, and the characterisation of this motion is the key to understanding the aetiology of the internal injuries. The type and severity of visceral injuries from blunt impact are dependent upon the magnitude of the deflection of the body wall, and most importantly upon the rate of the deflection.

An impact produces a force on the body wall, and consequently the body wall accelerates and its velocity increases. A bending load will be applied to structures within the body wall (such as ribs) and the local deflection arising from its motion will apply shear to the local underlying tissues. Depending upon the magnitude of this shear, local tissues may be lacerated or contused.

The increase in velocity of the body wall leads to the generation of stress (pressure) waves. The stress waves will propagate through the tissues and will reflect from effectively rigid structures within the body (such as the mediastinum or cranial vault) to result in a complex pressure environment within body compartments. The enhancement of stress waves by reflection and reinforcement may lead to "stress concentration" at particular foci, such as the contre-coup site in head injury, or the anterior borders of the lung. Stress waves lose energy when they encounter materials of different mechanical properties (the acoustic impedance - a function of the density and wave speed in the material). Tissue/air interfaces within lung parenchyma are particularly susceptible to energy transfer from stress waves. Disruption of the alveolar/capillary interface by the transferred energy will result in pulmonary contusion. Stress waves do not produce gross motion, but the forces within the tissue may be very high.

The propagated stress waves account for many of the distant injuries observed in high-speed BCT. Distant injuries may also be caused by shear waves. These are low velocity waves that cause gross motion of internal organs; a useful analogy is the wave that travels down a rope when it is whipped. The motion produced by shear may lead to strain (stretching) between organs and their sites of attachment, or produce local strain within organs resulting in contusion or laceration.

As a general principle therefore, in the characterisation of any type of nonpenetrating impact, the deflection of the body wall and the rate of the deflection (defined either by the peak acceleration or peak velocity of the body wall) must be defined. For slow, high momentum impacts such as those occurring in Road Traffic Accidents (RTA's), the peak velocity of the body wall may be relatively small, but the body wall deflection will be large (i.e. high local shear). The deflection may take tens of milliseconds to reach its maximum. At the other extreme, the impact of a very fast but lightweight blunt projectile (low momentum) will lead to very high body wall velocities (i.e. intense stress waves), but small body wall deflections. The time to peak body wall deflection may be only 1 or 2 milliseconds. The pathology arising from these two impact extremes may be different.

The challenge for developing protective measures to reduce the incidence and severity of BABT is to characterise the motion of the body wall behind the armours and thereby define the balance of local shear, stress waves and shear waves in the production of the injuries.

\section{Lateral thoracic impacts}

Much of the available knowledge of blunt injury mechanisms has been generated by the automobile industry. As discussed above, the injury mechanisms following RTA are characterised by low speed, large mass impacts transferring energy to the chest over a comparatively long time period. This is in direct contrast to ballistic impacts on ceramic plates, nevertheless some of the biophysical data from research aimed at reducing the incidence and severity of thoracic trauma from RTAs provides insight into the dynamic response of the chest to impact.

The chest wall under the impact point will accelerate to a peak velocity, which then decreases back to zero when the peak deformation is attained. It is the rate at which this deformation occurs and not its magnitude that is the injurious event. This feature was exemplified by experiments in which human volunteers had their chests compressed at $1 \mathrm{~m} / \mathrm{s}$ by up to $20 \%$ [this value is a relative deflection - the percentage reduction in chest dimensions in the same axis as the applied force] (Kroell 1976). They suffered no ill effects. In contrast, pigs showed an almost $100 \%$ probability of lung injury with $20 \%$ compression at a chest wall 

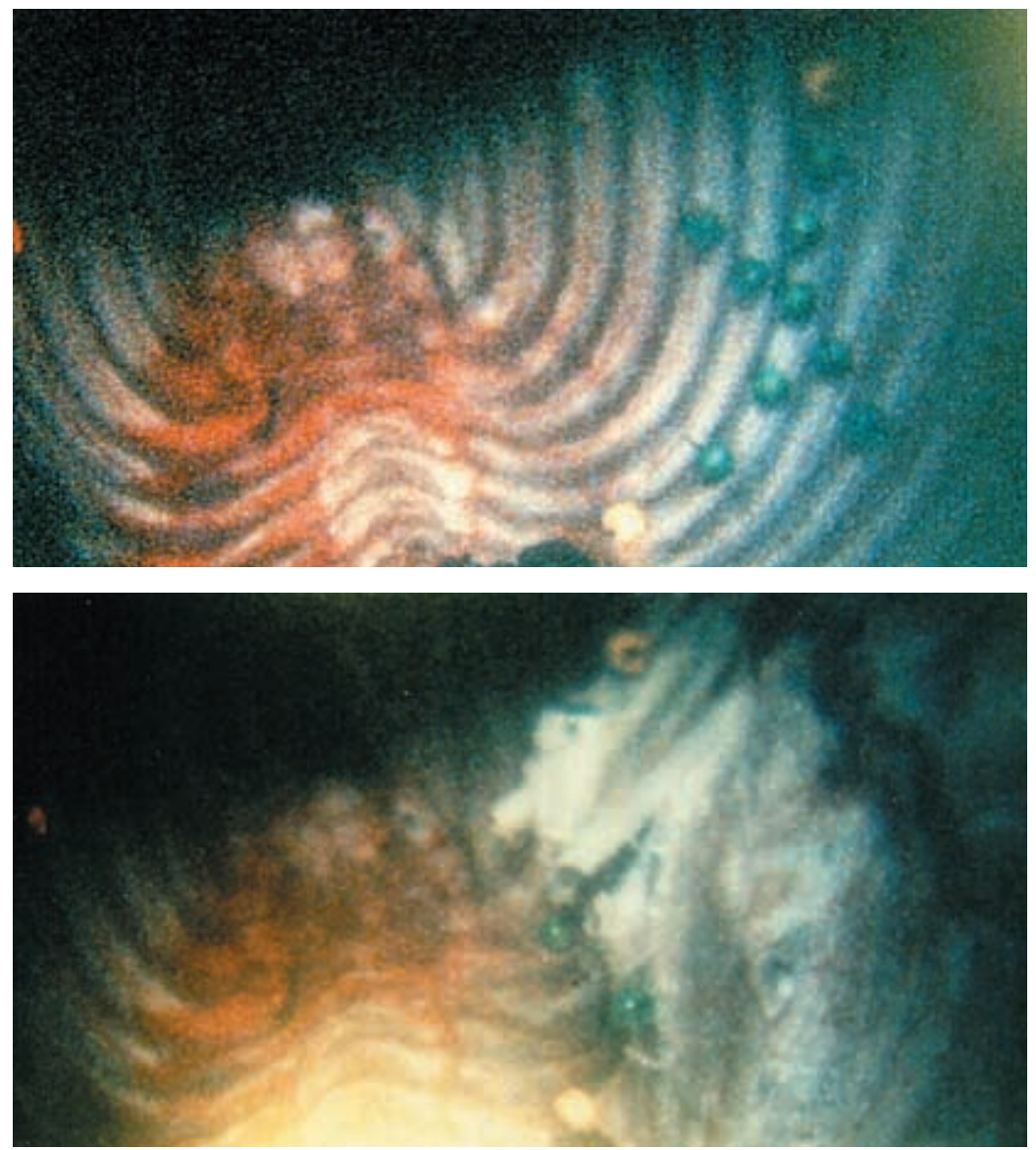

Fig 4. Deflection of the internal aspect of the left lateral thoracic wall following $12.7 \mathrm{~mm}$ bullet impact on a boron carbide plate placed on the external body wall. The model is the eviscerated thorax of a pig and the camera view is from the approximate position of the abdomen, looking anteriorly. The spine is at the bottom of the picture. Marker beads to track the motion of the internal aspect of the left body wall are attached to the pleural surface of the thorax (the beads are on the right side of the image). The pre-impact view is shown in the upper image. The deflection of the body wall a few milliseconds after the non-penetrating impact of the bullet on a plate placed over the left thorax is shown in the lower image. Fractured, displaced ribs are evident with gross intrusion of the body wall into the thoracic cavity.

velocity of $10 \mathrm{~m} / \mathrm{s}$ (Viano and Lau 1988). Relative chest wall displacements in pig thoraces of $27 \%$ (with attendant rib fractures) have been recorded following impacts with $12.7 \mathrm{~mm}$ rounds (Figure 4 ).

The human body is visco-elastic: its effective stiffness is dependent upon the rate at which it is compressed. Reflecting this behaviour, a 'Viscous Criterion' of blunt injury prediction to soft tissue was proposed in 1983 (Viano and Lau 1983). This criterion is the product of the time varying percentage of chest compression and the velocity of body wall deformation. The upper extreme of the criterion's validity with respect to velocity is approximately $30 \mathrm{~m} / \mathrm{s}$ (Viano and Lau 1988). Its validity in predicting injury as a result of BABT may be limited because body wall velocities may exceed this value

From first principles, the rate of rise of a stress wave generated in the body is probably dependent upon the peak acceleration attained by the chest wall following impact. It is possible therefore that peak body wall acceleration may be an appropriate index of the severity of injury from stress waves. Whole body peak acceleration has not been shown to be a satisfactory correlate or causal factor in RTA type lateral impacts (Kroell et al 1981) - undoubtedly because these impacts are relatively low speed, and whole body acceleration does not adequately represent the local acceleration of the body wall. In a study into the effects of air bag deployments, Lau et al (1993) used the premise that body wall acceleration was an important factor. Using computer modelling, peak chest wall acceleration was predicted to correlate with lung injury following high-speed blunt projectile impacts to the chest (Bush and Challener 1988).

In work on primary blast injuries, a good correlation was achieved between peak chest wall acceleration (above $10 \mathrm{~km} / \mathrm{s} / \mathrm{s}$ ) and the increase in lung weight - an index of the degree of haemorrhage and oedema in the lung (Cooper et al 1996a). One important difference between blast and BABT biomechanics is that an explosion will normally produce a shock wave loading that encompasses the whole thorax and is relatively uniform over the surface facing the explosion. However, thoracic stress wave loading from a BABT impact will originate from a specific locus on the thoracic wall (the impact point) and will propagate as a hemispherical wave from that point. Another important difference is that pulmonary contusions from blast interactions may be entirely dependent upon the propagation and interaction of stress waves (and therefore characterised by the peak acceleration or velocity of the body wall) with the gross deflection of the thoracic wall contributing little to aetiology of the injury (Cooper et al 1991). This is not likely to pertain to BABT where, because of the more localised loading, the gross deflection will be notable and will contribute to the observed pathology.

\section{Anterior thoracic impacts}

Less research has been undertaken on the biomechanical response of high speed impacts to the anterior thorax. The Viscous Criterion (VC) has been validated for predicting soft tissue injury following anterior RTA-type impacts (Viano and Lau 1988). With regard to peak acceleration, Nahum et al (1975) concluded that for RTAtype impacts, sternal acceleration did not correlate with injury severity. However in later experiments, an association was found between fatal ventricular fibrillation (VF) and peak acceleration (Viano and Artinan 1978). The production of dysrhythmias may be more important clinically than the presence of some types of cardiac damage as it is well recognised that cardiac contusions are usually well tolerated. The clinical signs are transient and difficult to recognise and the electro-physiological effects they produce are often idiosyncratic (Parmley 1958).

\section{Probable mechanism of BABT injury}

The biophysical principles of BABT injury 


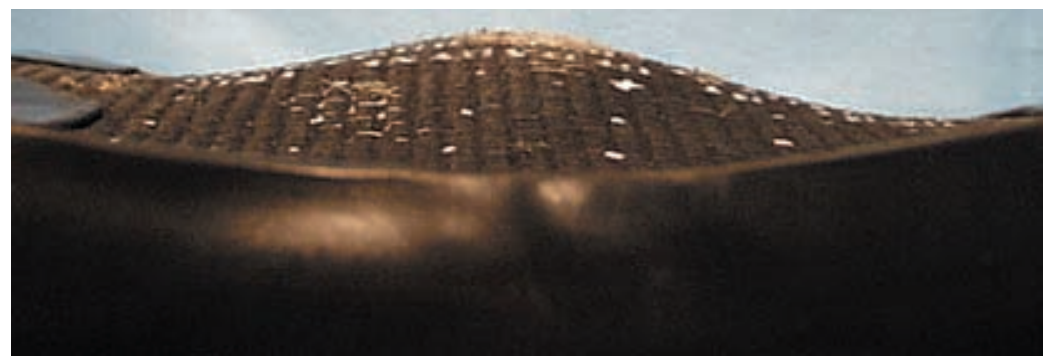

Fig 5. Residual deformation of $20 \mathrm{~mm}$ of the rear of a boron carbide plate - the dynamic deformation was greater.

are the subject of current research, but the following sequence is an informed prediction of events following the impact of a high energy bullet on a ceramic armour plate directly against the body wall:

- The contact of the bullet on the hard face of the ceramic plate generates a very short duration stress wave (van Bree and van der Heiden 1996). This wave propagates through the plate and its backing, and couples directly into the body. This is an extremely fast event with no significant gross motion of the plate or body wall.

- The debris from the erosion of the bullet by the ceramic applies a load to the backing of the plate and the rear of the backing accelerates and deforms locally beneath the bullet contact point. The residual deformation may be relatively small (Figure 5), but the dynamic deflection will be greater, and occurs at high speed.

- The localised motion of the plate backing applies a load to the surface of the body wall. The superficial tissues of the body wall compress, reducing the thickness of the body wall. The inner aspect of the body wall starts to accelerate and soon attains a peak velocity. This dynamic motion generates a second stress wave that is propagated into the body and may produce pathology both locally and at distant sites, and electro-physiological effects.

- The gross deflection of the body wall increases and applies local shear to tissues immediately underneath the deflection - for example: pulmonary contusion; myocardial contusion; liver laceration, depending on impact location. Figure 4 shows the gross deflection of the interior aspect of the thoracic wall following non-penetrating impact of a $12.7 \mathrm{~mm}$ round on a ceramic plate placed on the outside of the thorax.

- As the deflection increases, shear waves are propagated through tissues leading to gross motion of organs. Ribs (or sternum) may be fractured by the high forces within the body wall and displaced through the inner aspect to produce local lacerations to underlying tissue.

- The plate as a whole will also gain velocity imparted by the impact of the bullet (the conservation of momentum) and the whole plate may then apply a more distributed load to the body.
Thus, the aetiology of BABT is complex and its prevention requires an integrated approach to dissipate and absorb energy over different time-scales. Attenuating one form of energy transfer may exacerbate another form. It is also necessary to ensure that methods used to alleviate the biological effects of the energy by placing materials between the armour plate backing and the body wall do not compromise the performance of the plate with regard to stopping the projectile.

\section{Pathophysiology of BCT}

The pathophysiological consequences of BABT from high available energy impacts are currently under investigation, but an overview of BCT from general nonpenetrating impacts will offer insight into the likely pathology.

\section{Chest wall}

A range of soft tissue and bony injuries can result following BCT. There may be no outward signs of chest wall injury despite marked pulmonary insufficiency (Alfano and Hale 1965). While rib fractures are merely used as a guide to visceral damage following civilian accidents, the presence of rib fractures in combat troops may result in military incapacitation. An important point to be made is that the extent of injuries to the chest wall cannot be used to predict the extent and nature of intrathoracic injuries, such is the idiosyncratic nature of the production of indirect injuries following BABT (Carroll and Soderstrom 1978). Indeed, even in experimental models subjected to apparently identical energy transfers, the degree and pattern of injury can be unpredictable (Baosong et al 1996).

\section{Lung}

Although a wide range of pulmonary injuries can result following BCT, the typical if not pathognomonic lesion is the lung contusion. Little attention was paid to contusions until a number of reports emerged during and after WW II as a result of studies into the effects of blast waves (Ross 1941, King and Curtis 1942). The characteristic histological findings consist of localised haemorrhage and oedema in the alveoli and the interstitial spaces (Alfano and Hale 1965), Fulton and Peter 1970). In a departure from this histopathological description, Wagner et al (1988) used computerised tomography (CT) to investigate clinical cases of BCT and found that the basic component of the majority of lung contusions were lacerations of the alveoli or alveolar septae. The cause of this epithelial-endothelial disruption has been attributed to stress waves (Cooper and Taylor 1989, Baosong et al 1996) and tensile forces across the alveoli (Fung et al 1988).

Acute respiratory distress syndrome (ARDS) complicates up to $26 \%$ of cases of 
significant BCT associated with pulmonary contusions (Pepe 1989). First recognised during WW II (Burford and Burbank 1945), the condition has been described by a variety of names including 'contusion pneumonitis' and 'traumatic wet lung'. Pneumonia may complicate BCT in $5-10 \%$ or more of cases (Pepe 1989) rising to $85 \%$ if there is a coexisting flail segment (Clark et al 1988). This is in contrast to an incidence of less than $5 \%$ following penetrating chest trauma (Pepe 1989). Pulmonary contusions may predispose to pulmonary infection by producing a reduced ability to cough and thus to clear secretions and by directly reducing the clearance of bacteria (Richardson et al 1979).

\section{Heart}

Following RTA-type impacts, the anteroposterior (AP) displacement of the chest wall is large (often exceeding 50\%) and the cardiac injury pattern is thus predominated by crushing (local shear). The principal consequence of RTA BCT affecting the heart is trauma to the myocardium accounting for more than $90 \%$ of all cardiac lesions (Parmley et al 1958). In experiments on anaesthetised pigs using high speed blunt projectiles, $54 \%$ were found to have areas of contusion with ruptures in $29 \%$. A number of contusions were situated adjacent to the coronary vessels as well as in seemingly random areas (Cooper et al 1982). This led the authors to speculate in later papers (Cooper et al 1984, Cooper and Taylor 1989) that this distribution of contusions was dictated by the propagation of stress and shear waves rather than direct trauma.

Cardiac contusion may lead to dysrhythmias, due to altered electrical characteristics with respect to normal myocardium (Pearce and Blair 1976). Tachyarrhythmias, bradyarrhythmias and ventricular ectopic foci may arise from these areas. The other effect of large areas of contusions is myocardial pump failure. This feature includes a spectrum of outcomes encompassing transient cardiac depression and cardiogenic shock.

In addition to the coronary arteries, the thoracic aorta and its arch divisions can be injured in BCT. The location and type of vessel injury depends on the forces acting upon them and the degree of displacement of the vessel. The aortic isthmus is particularly prone to injury as it marks the junction between the relatively mobile aortic arch and the fixed descending aorta. In patients with thoracic aortic trauma due to BCT, isthmic damage is present in $80-90 \%$ of patients (Pretre and Chilcott 1997).

The early dysrhythmias constitute the most immediate and life-threatening situation (other than myocardial rupture) to arise from BCT affecting the heart. Ventricular fibrillation (VF) and transient complete heart block are the two most commonly encountered in experimental pig models (Cooper et al 1982, Link et al 1998). Variable periods of transient 'cardiac standstill' are often seen which do not appear to result in any significant degree of morbidity. VF is the more common, and the one most likely to result in death if defibrillation is not attempted. If the human patient survives the initial impact, a plethora of other rhythm disturbances may follow. These include atrial fibrillation, premature ventricular contractions, bundle branch blocks and sinus bradycardia (Baxter et al 1989). These complications invariably occur within the first 12 hours post-impact.

\section{Thoracic surrogates for prediction of BABT}

The current standard for the predicted occurrence of BABT behind armours is promulgated by the US National Institute of Justice (NIJ, 1987). This standard stipulates a maximum level of post-impact static indentation in clay of $44 \mathrm{~mm}$; this is taken as a pass/fail criterion for BABT. The standard principally addresses the deformation of soft, flexible body armours attacked by low energy-transfer bullets. This standard does not address a key feature of BABT - that the impact is a dynamic event and the motion of the body wall is the prime factor coupling energy into the body. Plainly, measurement of a static indentation in a medium such as clay cannot represent this event. This deficiency is widely recognised, but in the absence of data defining the relationship of the dynamic response of the body wall to loading by the rear face of an armour and BABT, the standard does at least offer the commercial developers of armours a performance target to reduce the trauma from localised thoracic wall deflection.

A physical model simulating the effects of blast on the thorax has been developed by DERA Porton Down (Cooper et al 1996b); it uses peak acceleration of a physical representation of the body wall as the sole measured output for simple blast waves (a different biophysical indicator is used for complex blast waves). The peak acceleration of the wall of the model correlates with the severity of lung contusion (assessed by an increase in lung weight). This approach is now being extended to design a thoracic wall material that will replicate the deflection and motion of a pig thoracic wall subjected to BABT loading (Tam 1999). The BABT rig (Figure 6) consists of a silicone rubber 'chest wall' mounted in a support system. The required mechanical properties of the model wall were determined by reviewing historical data on the response of the lateral thoracic wall of anaesthetised pigs to high-speed nonpenetrating impacts, limited BABT data from dead pig models and mathematical 


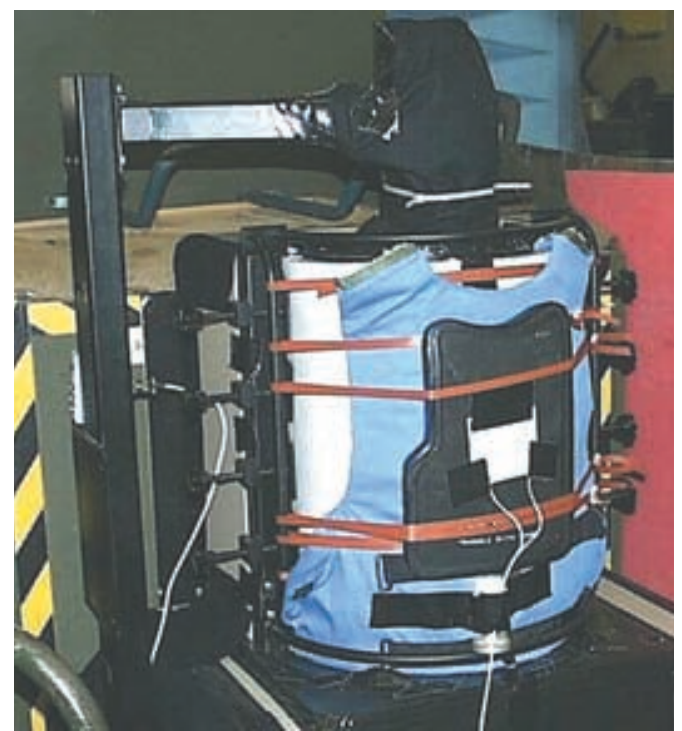

Fig 6. The BABT rig: a boron carbide plate and flexible combat armour system have been placed over the white silicone rubber wall that replicates the dynamic motion of the pig body wall. The rapid deflection of the wall is detected by sequential obstruction of an fan of laser beams behind it (not visible in the image).

models of body wall dynamics developed from these data. The motion of the rear of the model body wall is determined by a noncontacting laser system that tracks its motion. The wall velocity and acceleration can be calculated from this data. The system as currently implemented can rank the BABT potential of armour plates and TABs. It is being enhanced to enable an absolute prediction of BABT injury, and thereby offer dynamic performance targets for protection from BABT.

Other workers have also realised the need for specific, validated models of localised, non-penetrating chest trauma. One such system, termed the 3-rib chest structure, has been designed to study the injury potential of non-lethal weapons (such as riot control projectiles). Its output is peak velocity from which the maximum Viscous Criterion (VCmax) can be calculated and as its designers point out, $\mathrm{VC}_{\max }$ can only predict injury if the chest wall deformation velocity is between 3 and $30 \mathrm{~m} / \mathrm{s}$ (Bir and Viano 1998). Experiments at Porton Down have measured peak inner chest wall velocities following $12.7 \mathrm{~mm}$ bullet impact in excess of $50 \mathrm{~m} / \mathrm{s}$.

Haley et al (1996) used the Hybrid III anthropomorphic 'crash test dummy' in a BABT test in which $12.7 \mathrm{~mm}$ calibre rounds were fired against ceramic plates. They recorded the average displacement of the rear of the armour plate as 0.7-0.8 inches. They recognised that a significant time span elapsed between frames and commented that an element of rebound of the chest wall may have occurred in the time span between frames. Also, the residual permanent deformation may not reliably represent the extent of true deformation because it takes no account of the dynamic nature of the deformation.
Jonsson et al (1988) used a modified version of the Hybrid III dummy to predict lung injury following BABT. They placed pressure transducers into foam lung models within the Hybrid III thorax and recorded the pressure profiles following various levels of BABT loading. They made the assumption that the injury patterns following blast were similar to those following BABT. They found no direct proportionality between projectile mass, velocity or Kinetic Energy and intrathoracic pressure - an index of blunt injury potential.

\section{Guidelines for the clinical management of high energy BCT}

\section{Diagnosis}

The management of BCT in field conditions relies totally on the recognition of the condition and the diagnostic aids available. The immediately life threatening thoracic injuries can all be diagnosed on clinical examination and imaging should play little or no role in the diagnosis of these injuries. The injuries presenting to the field medical officer are probably self-selecting and those with gross injuries are usually apparent. The difficulty will lie in those patients with little in the way of early pathology, but in whom pathology may evolve over a period of hours. The diagnosis of chest wall and thoracic organ injury by special investigations in terms of civilian BCT is still a matter for considerable debate. The main reason for this is the often inconsistent correlation between detectable injury and clinical effects.

\section{Lung injuries}

The supine anteroposterior chest radiograph is one of the initial investigations routinely performed on the trauma victim. The limitations of this investigation are well documented. Approximately $30 \%$ of traumatic pneumothoraces are missed on supine radiographs (Wall et al 1983) and on erect radiographs it has been shown that 500 $\mathrm{ml}$ of blood is required to fill the costophrenic recess sufficiently to allow the diagnosis of haemothorax to be made (Collins et al 1972). Similarly, 21\% of experimentally produced pulmonary contusions in dogs were missed by radiographs 6 hours post-injury although all were visible on computerised tomography (CT) scans (Schild et al 1989).

\section{Heart injuries}

Virtually every type of electrocardiograph (ECG) change has been associated with BCT to the heart but no change is pathognomonic (Unkle et al 1989). ECG's have a high false-positive and false-negative rate for BCT. Parmley et al (1958) induced chest trauma to animals and recorded a 
variety of ECG changes despite the absence of injury at autopsy. Conversely, Blair et al (1971) described patients with normal ECGs and autopsy-proven myocardial contusion (the patients dying of comorbidity). However, the ECG does have an important role to play in the management, if not the diagnosis, of cardiac BCT - it is the haemodynamic compromise resulting from the dysrhythmia that is important, not necessarily the absolute diagnosis of contusions (Baxter et al 1989, Healey et al 1990).

More recently, the role of helical CT has been investigated. It was found to give a level of $100 \%$ sensitivity and 99.7-99.8\% specificity (Mirvis et al 1998, Wicky et al 1998). One group recommends that all trauma patients with suspected aortic injury undergo helical CT evaluation and that it should replace aortography as a screening tool (Demetriades et al 1998). As mobile helical CT scanners are to be deployed with $\mathrm{UK}$ forces in the near future, its use in the evaluation of BCT needs to be examined.

\section{Treatment}

Following recognition of the extent of the injuries, the treatment of BCT (BABT) injuries will be largely supportive. Drainage of a haemopneumothorax and cardiac monitoring have been employed (Jourdan 1995) and are within the skills of most medical officers. Following civilian BCT and because of the variability in electrophysiology and the poor sensitivities and specificities of diagnostic tests, some authors argue that cardiac monitoring for a 24-hour period is a pragmatic and sensible approach (Baxter et al 1989, Healey et al 1990). This would seem a sensible approach for BABT injuries (local circumstances permitting).

\section{Concluding remarks}

It is a false assumption that eliminating the penetration of a projectile into the body by using a personal armour system absolves the wearer from serious injury or death. The kinetic energy of the projectile must be dissipated; the key is to ensure that the proportion of this energy which is coupled into the body is minimised, or is transferred over an extended time-scale or surface area. However, the design of a trauma attenuating backing placed between an armour plate and the body to enable this re-distribution of energy, must also ensure that the ballistic performance of the plate is not compromised. This is a very difficult balance, and the tradeoffs can only be determined with knowledge of the biophysical principles of the transfer of the energy of the projectile into the body. There are a number of co-ordinated research activities within NATO addressing this issue. Behind Armour Blunt Trauma is not an insurmountable problem but its emergence requires innovative technical solutions. The art is to attenuate the injury using solutions that do not increase the burden to the soldier, but offer to the designers of heavy, rigid ballistic plates an opportunity to reduce plate weight and bulk. This may only be achieved with control over how and where the energy of the bullet will be dissipated safely.

\section{References}

Alfano GS, Hale HW. Pulmonary contusion. F Trauma 1965; 5(5): 647-656.

Baosong L, Zhengguo W, Huaguang L, Zhihuan Y, Xiaoyan L. Studies on the mechanisms of stress wave propagation in chest subjected to impact and lung injuries. F Trauma 1996; 40(3): S53-55.

Baxter BT, Moore EE, Moore FA et al. A plea for sensible management of myocardial contusion. $A m \mathcal{F}$ Surg 1989; 158: 557-561.

Bir CA, Lyon DH, Viano DC. Development of a lowcost, portable surrogate - the 3-rib chest structure. Non-lethal defense meeting III. Johns Hopkins Applied Physics Lab, 1998: 25-26.

Blair E, Topuzulu C, Davis JH. Delayed or missed diagnosis of cardiac damage in blunt chest trauma. $\mathcal{F}$ Trauma 1971; 11: 129.

Burford TH, Burbank B. Traumatic wet lung: observations on certain physiologic fundamentals of thoracic trauma. F Thorac Surg 1945; 14: 415-424.

Bush IS, Callener SA. Finite element modelling of non-penetrating thoracic impact. In Proceedings of the 1988 conference of the International Research Committee on Biokinetics of Impacts (IRCOBI), September 1988.

Carroll AW, Soderstrom CA. A new non-penetrating ballistic injury. Annals of surgery 1978; 188(6): 735-7.

Clark GC, Schecter WP, Trunkey DD. Variables affecting outcome in blunt chest trauma: Flail chest v's pulmonary contusions. F Trauma 1988; 28: 298-304.

Coates JB, Beyer JC. Wound ballistics. Office of the Surgeon General. Department of the Army. Washington, DC, 1962.

Collins JD, Burwell D, Furmanski S et al Minimal detectable pleural effusions. A roentgen pathology model. Radiology 1972; 105: 51-53.

Cooper GJ, Maynard RL, Pearce BP, Stainer MC, Taylor DEM . The biomechanical response of the thorax to nonpenetrating impact with particular reference to cardiac injuries. F Trauma 1982; 22(12): 994-1008.

Cooper GJ, Maynard RL, Pearce BP, Stainer MC, Taylor DEM. Cardiovascular distortion in experimental nonpenetrating chest impacts. F Trauma 1984; 24(3): 188-200.

Cooper GJ, Pearce BP, Sedman AJ et al Experimental evaluation of a rig to simulate the response of the thorax to blast loading. F Trauma 1996b; 40(3) Suppl : S38-41. Cooper GJ, Taylor DEM. Biophysics of impact injury to the chest and abdomen. F R Army Med Corps 1989; 135:58-67.

Cooper GJ, Townend DJ, Cater SR et al. The role of stress waves in thoracic visceral injury from blast loading: modification of stress transmission by foams and high-density material. I Biomechanics 1991; 24: 273-285.

Cooper GJ. Protection of the lung from blast overpressure by thoracic stress wave decouplers. $f$ Trauma 1996a; 40(3): S105-110.

Demetriades D, Gomez H, Velmahos G et al. Routine helical computed tomographic evaluation of the mediastinum in high-risk blunt trauma patients. Arch Surg 1998; 133: 1084-1088.

Fulton RL, Peter ET. The progressive nature of pulmonary contusion. Surgery 1970; 67(3): 499-506.

Fung YC, Yen RT, Tao ZL, Liu SQ. A hypothesis on the mechanisms of trauma of lung tissue subjected to impact load. F Biomechanical Engineering 1988; 110: 50-56.

Gotts PL. Thoracic response to defeated body armour. In 'Rear effects of protection' NATO Technical Report AC/243(panel 8)TR/23 (Unclassified) $26 \mathrm{Feb} 1998 \mathrm{a}$. 
Gotts PL. Personal armour against small arms ammunition: UK MOD solutions. In proceedings of the XIIth European Small Arms and Cannon Symposium (Unclassified). Shrivenham. Aug 1998b. Haley JL, Alem NM, McEntire JB, Lewis JA. Force transmission through chest Armour during the defeat of a .50 calibre round. US Army Aeromedical Research Laboratory, Fort Rucker, Alabama. Report No. 96-14, Feb 1996.

Healey MA, Brown R, Fleiszer D. Blunt cardiac injury: Is this diagnosis necessary? F Trauma 1990; 30(2):137146.

Jane's Ammunition Handbook. Jane's Information Group Ltd, Surrey, UK.1999.

Jane's Infantry Weapons. Jane's Information Group Ltd, Surrey, UK.1999.

Jonsson A, Arvebo E, Scantz B. Intrathoracic pressure variations in an anthropomorphic dummy exposed to air blast, blunt impact and missiles. F Trauma 1988; 29(1) Suppl: S125-131.

Jourdan PH Behind Body armour effect. Case Report. Defence Research Group Panel 8 STBA Collaborate 10-12 Oct 95.

King JD, Curtis GM. Lung injury due to the detonation of high explosives. Surg Gynecol Obste1942; 74: 53-62

Knudsen PJT. In proceedings of the 3rd Meeting of the Specialist Team on Body Armour. Conclusions of STBA. NATO Unclassified. San Diego, USA, 23-25 April 1996.

Knudsen PJT. Preface. In 'Rear effects of protection' NATO Technical Report AC/243(panel 8)TR/23 (Unclassified) $26 \mathrm{Feb} 1998$.

Kroell CK, Pope ME, Viano DC et al. Interrelationship of velocity and chest compression in blunt thoracic impact to swine. In proceedings of the 25th Stapp Car Crash Conference. Warrendale, PA: Society of Automotive Engineers. Paper No. 811016 p549-582 1981.

Kroell CK. Thoracic response to blunt frontal loading. The Human Thorax - Anantomy, Injury and Biomechanics. Society of Automotive Engineers. Warrendale, PA. Paper No 67 p 49-78 1976.

Lau IV, Horsch JD, Viano DC, Andrzejak DV. Mechanism of injury from air bag deployment loads. Accid Anal Prev 1993; 25(1): 29-45.

Link MS, Wang PJ, Pandian NG et al. An experimental model of sudden death due to low-energy chest-wall impact (commotio cordis). N Engl f Med 1998; 338(25): 1805-11.

Mehran R, Connely P, Boucher P, Berthiume E. Modern war surgery: the experience of Bosnia 2: the clinical experience. Can f Surg 1995; 38(3): 338-346. Mirvis SE, Shanmuganathan K, Buel J, Rodriguez A. Use of spiral computed tomography for the assessment of blunt trauma patients with potential aortic injury. $\mathcal{F}$ Trauma 1998; 45(5): 922-930.

Nahum AM, Schneider DC, Kroell CK. Cadaver skeletal response to blunt thoracic impact. In proceedings of the 19th Stapp Car Crash Conference. Society of Automotive Engineers. Paper No. 751150 p259-293 1975.
National Institute of Justice. Ballistic Resistance of Body Armour - NIJ Standard 0101.03. April 1987

Parmley L, Manion WC, Mattingly TW. Nonpenetrating traumatic injury of the heart. Circulation 1958; 18: 371

Pearce W, Blair E. Significance of the electrocardiogram in heart contusion due to blunt trauma. F Trauma 1976; 16: 136.

Pepe PE. Acute post-traumatic respiratory physiology and insufficiency. Surg Clin North Am 1989; 69: 157173.

Peterson HL. Body armor in Civil War. Ordnance 34: 432-433 1950

Pretre R, Chilcott M. Blunt trauma to the heart and great vessels. NEFM 1997; 336 (9): 626-632

Richardson JD, Woods D, Johanson WG et al. Lung bacterial clearance following pulmonary contusion. Surgery 1979; 86: 730

Ross JM. Haemorrhage into the lungs in cases of death due to trauma. Br Med f 1941; 1: 79-80.

Schild HH, Strunk H, Weber W et al. Pulmonary contusions: CT vs plain radiograms. $\mathcal{F}$ Comput Assist Tomogr 1989;13: 417.

Shepard GH, Ferguson JL, Foster JH. Pulmonary contusion. Ann Thorac Surg 1969; 7(2): 110-119.

Tam W. Development of a behind armour injury simulator. In proceedings of the 3rd meeting of the Task Group on Behind Armour Blunt Trauma. NATO Unclassified. Washington, USA. 20-23 April 1999.

The Sunday Times. 7 May, page 3. 2000.

Thomas GE. Fatal .45-70 rifle wounding of a policeman wearing a bullet-proof vest. Fournal of Forensic Sciences 1982; 27(2): 445-449.

Unkle DW, Smejkal R, O'Malley KF. Myocardial contusion without creatine kinase-MB elevation. Heart Lung 1989; 18: 539-541.

Van Bree JLMJ, van der Heiden N. Behind armour pressure profiles in tissue simulant. In Proccedings of the Personal Armour Systems Symposium 1996 Colchester UK. 3-6 Sep 1996.

Viano DC, Artinan CG. Myocardial conducting system dysfunction from thoracic impact. 7 Trauma 1978; 18(6): 452-459.

Viano DC, Lau IV. A viscous tolerance criterion for soft tissue injury assessment. F Biomechanics 1988, 21(5): 387-399.

Viano DC, Lau VK. Role of impact velocity and chest compression in thoracic injury. Aviat Space Envir Med 1983; 54: 16-21.

Wagner RB, Crawford WO, Schimpf PP. Classification of parenchymal injuries of the lung. Radiology 1988; 167: 77-82.

Wall SD, Federle MP, Jeffrey RB, Brett CM. CT diagnosis of unsuspected pneumothorax after blunt abdominal trauma. American $\mathcal{F}$ of Roentgenology 1983; 141: 919-921.

Wicky S, Capasso P, Meuli R et al. Spiral CT aortography: an efficient technique for the diagnosis of traumatic aortic injury. Eur Radiol 1998; 8(5): 825833. 